\title{
Discussion on Electric Field Analysis Simplified Modeling of Electrical Equipment
}

\author{
Zonghan $\mathrm{Li}^{1, \text { a }}$ \\ School of Electric and Electronic Engineering, North China Electric Power \\ University ,Beijing ,102206, China \\ a310153630@qq.com
}

Keywords: Electrical equipment; power plant analysis; converter valve; simplified modeling

\begin{abstract}
With the rapid development of extreme high voltage technology, more large-scale electrical equipments are gradually put into use. However, due to the complexity of these devices on structure, and the electric field calculation in equipment operation will be confronted with great difficulties. Therefore, the corresponding simplified modeling method should be introduced to realize safe and stable operation of power system. This paper mainly analyzes the necessity of the simplified modeling of electrical equipment in the electric field to explore the construction idea of electrical model which is represented by converter valve.
\end{abstract}

\section{Introduction}

With the rapid construction of electric system in China, extreme high voltage and ultra high voltage has become the main direction of the electric power system development. For example, high-voltage direct current transmission technology introduced in power grid construction makes it possible to realize the DC project construction objective. However, due to the complex equipments involved in high-voltage direct current transmission line, the stable operation of power system may be affected if the power plant monitoring of equipment surface is ignored. Therefore, the analysis of simplified modeling of equipment electric field in this paper has important significance.

\section{The necessity of the simplified modeling of equipment electrical field}

The current domestic direct current transmission systems applied in most direct current projects are presented as alternating current and direct current transmission lines, grounding electrode lines, inverters and converter stations on the constitution. Take the convertor station as an example which is an important device of conversion between direct current and alternating current. The conversion valve system is the key factor to realize the conversion. Therefore, the converter valve in direct current convertor station is called the "heart". The converter valve forms a three-phase rectifier bridge through thyristors in series. In the operation process, the overvoltage from both the DC system and AC system will be applied in it. At the same time, the corresponding flat wave reactor and converter transformer will be set at both DC side and AC side in the valve system. When the lightning overvoltage invades, isolator will withstand part of overvoltage. Assume that the ground fault exists in smoothing reactor, the overvoltage generated in converter valve will presented as impulse voltage waveform. Similarly, when ground fault exists in the internal valve of convertor station, there will voltage which is close to the lightning overvoltage, which will lead to great threaten to the equipment and the whole electric system. Therefore, the converter outer current and floating potential should be consider to fully grasp the electric field distribution of the equipment. Thus the parameter adjustment and insulation will be possible. The electric field analysis largely depends on the corresponding numerical calculation of electromagnetic field and the simplified modeling method. Thus the electric field distribution will be predicted efficiently, which provides corresponding reference for insulation design and the adjustment of electric field parameters distribution. Therefore, the simplified modeling is very necessary for the equipment electric field. 
The specific ideas of model building for HVDC converter valve

This paper takes converter valve as the example to study analysis simplified modeling of electric equipment. The reason is that it is the main equipment in direct current transmission system. It not only presents the functions of inverter and rectification, also realizes the rapid outage and start of direct current transmission through the switch function of rectification station. The electric field calculation and simplified modeling idea of the device are presented in the following aspects specifically.

\section{The analysis of structure and characteristics of converter valve}

The electrical structure of converter valve mainly consists of valve module and valve tower. Valve module is presented in thyristor converter valve. This component includes not only thyristor, also a corresponding voltage-sharing element and the anode reactor. Furthermore, all components are conducted with electrical connection with technical means. Generally speaking, in the valve structure, the silicon controlled rectifier composed of the thyristor and parallel damping loop is the most basic unit. On the basis, the series connection of the electric reactor and five silicon controlled rectifiers can form a valve assembly, which is the basic unit of valve module. The valve tower is composed of 12 valve modules in series, basing on which 4 shielding plates are integrated. The quadruple-valve formed in this way is valve tower. In addition, the main characteristics of the converter valve mainly include: Firstly, electrical characteristics. Take the 12-pulse converter valve as an example, its electrical characteristics are mainly displayed in the main forward conduction, whereas the valve without conduction will bear the voltage from reverse blocking and forward blocking. The voltage value is required to be determined on the basis of the protection level of the arrester. At the same time, since the valve is switched between the open and closed state, it is difficult to automatically turn off. The valve itself should have the ability of over current. The over current amplitude can be determined according to the change of short-circuit impedance changes and short circuit capacity of the system. Secondly, component characteristics, since converter valve components are mainly composed of the thyristor, the characteristics of thyristor are those of valve element, including the voltage increasing situation under the critical of on or off state, gate level characteristics and anode volt-ampere characteristics. Generally speaking, the valve design should not only consider making it possible to solve the problem of reduction of the quantity of components in series and the inhomogeneous voltage distribution, also pay attention to the full use of electric current capacity of thyristor.

Converter valve system structure description

Converter valve system structure is mainly manifested in the aspects of shielding case and monolayer converter valve. Take the converter shielding case as an example. Assume that the valve hall contains two groups of 6-set valve tower with 10 layers, 8 layer converter valve and the 2 shielding layer. The shielding case set outside the valve is the main object of the electric field calculation, and its model can be constructed combining with the relevant capacitance parameters in the electric field. See details in Figure 1. 


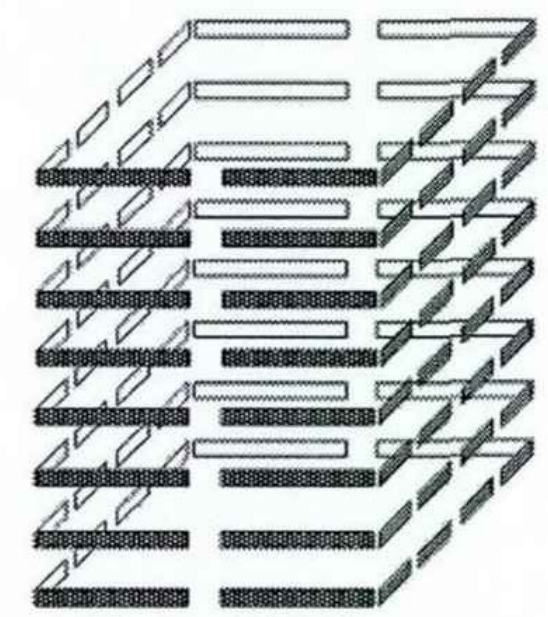

Figure 1 Valve tower shielding case model

In addition, the converter valve system structure is also reflected in the single layer valve structure. Generally speaking, this structure is composed of 4 electric reactor modules and 4 thyristor modules. These modules are mainly arranged in rectangle mode. Each module unit is connected with the reactor components in series, and the thyristor components in these modules have corresponding voltage divider , control unit, and snubber circuit. See details in Figure 2.

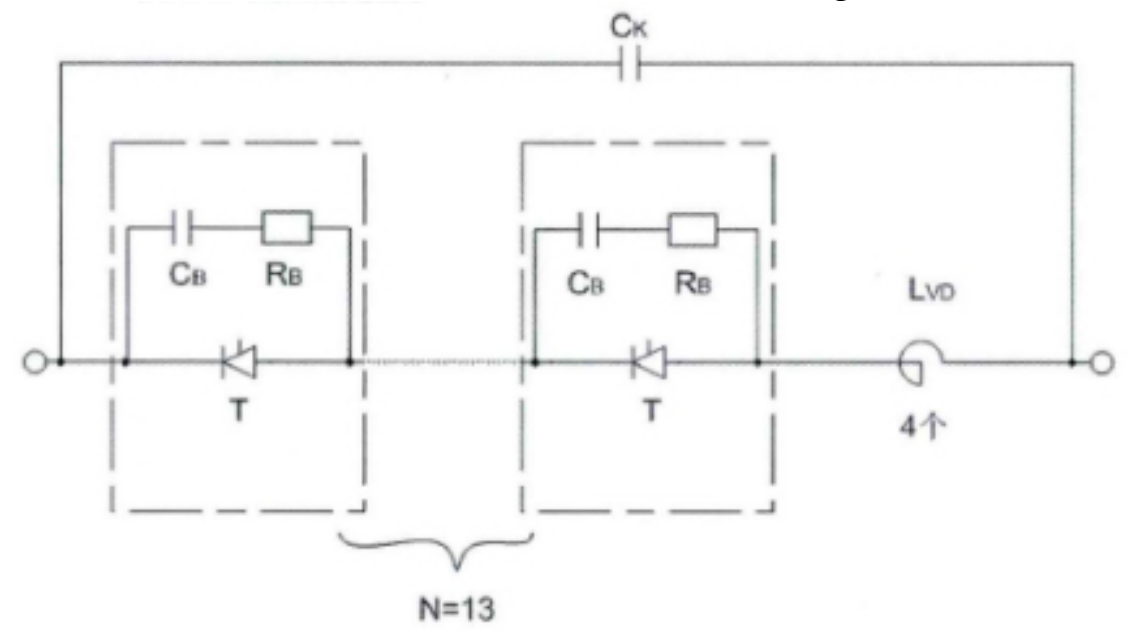

Figure 2 Schematic diagram of single valve structure

The specific method to simplify the modeling of converter valve

In the process of converter valve simplified modeling, this paper mainly introduces Ansys software modeling method, and calculates the electric field distribution situation through fortran. The relevant contents are mainly concentrated in the shielding case model under single-layer, three-layer and the whole converter valve. Firstly, in the modeling of the single-layer shielding case, the palne unit subdivision should be carried out. Choose two plane units and the corresponding electric field distribution situation, and apply $0 \mathrm{kv}$ and $500 \mathrm{kV}$ voltage respectively on the three plates at the low right and other plates. Thus the corresponding results can be calculated. When the simplified modeling is completed, the reference plane is selected as plane unit subdivision form, while the other parts can uitilize line unit subdivision methods. Therefore, the electric field distribution situation can be estimated. Similarity, apply $0 \mathrm{kv}$ on the one plate at the low right and 500kv to other wireframe parts. The corresponding calculation results can be obtained. The study shows that the introduced fortran algorithm allow the judgment of the shield surface electric field distribution, shown as Table 1. 
Table 1 the electric field distribution result of shielding case based on the fortran calculation

\begin{tabular}{|l|c|c|c|c|c|c|c|c|}
\hline & 1 & 2 & 3 & 4 & 5 & 6 & 7 & 8 \\
\hline $\begin{array}{l}\text { Single } \\
\text { line } \\
\text { model }\end{array}$ & $4873 \mathrm{~V} / \mathrm{m}$ & $4615 \mathrm{~V} / \mathrm{m}$ & $7947 \mathrm{~V} / \mathrm{m}$ & $2602 \mathrm{~V} / \mathrm{m}$ & $7950 \mathrm{~V} / \mathrm{m}$ & $4536 \mathrm{~V} / \mathrm{m}$ & $3545 \mathrm{~V} / \mathrm{m}$ & $4998 \mathrm{~V} / \mathrm{m}$ \\
\hline $\begin{array}{l}\text { Single } \\
\text { plane } \\
\text { model }\end{array}$ & $5240 \mathrm{~V} / \mathrm{m}$ & $4963 \mathrm{~V} / \mathrm{m}$ & $8545 \mathrm{~V} / \mathrm{m}$ & $2789 \mathrm{~V} / \mathrm{m}$ & $8549 \mathrm{~V} / \mathrm{m}$ & $4877 \mathrm{~V} / \mathrm{m}$ & $3812 \mathrm{~V} / \mathrm{m}$ & $5375 \mathrm{~V} / \mathrm{m}$ \\
\hline
\end{tabular}

Table 1 shows that there are few errors between the result obtained from simplified modeling and the electric field distribution before the simplification. The quantity of unit and node before simplification are 1718 and 1748 respectively, whereas those after the simplification are 1333 and 1238.

Secondly, the three-layer shield model also utilizes the single-layer shielding case electric field distribution analysis method. That is to say, adopt the method of subdivision plane unit before the simplified modeling. Select two reference planes and judge its electric field distribution situation. Apply $0 \mathrm{kv}$ and $500 \mathrm{kV}$ voltage respectively on the plates at the low right and other plates, and the calculation will be completed. The introduction of fortran algorithm will lead to about $7 \%$ error between the electric field distribution results obtained before and after simplification.

Finally, as for the overall shielding case electric field distribution, introduce the same method as monolayer, three-layer shield simplified model. And the error can be controlled within $10 \%$. On the basis of the combination of electrical characteristics and components characteristics of converter valve structure, introduce corresponding modeling method and calculation method, the electric field analysis result of single layer, three-layer or whole shielding case can be speculated through the simplified modeling, and the calculation speed and precision can be guaranteed. Therefore, in actual calculation of electrical equipment electric field, the simplified modeling method can be introduced.

\section{Conclusion}

The simplified modeling is an important way to analyze the electric field of electrical equipment. The actual simplified modeling, we should have a correct understanding on its necessity. According to the main characteristics and structure of electrical equipment, introduce the corresponding modeling and calculation method, in order to achieve the goal of electric field distribution calculation. This paper selects the converter valve as an example to prove the necessity and feasibility of the simplified modeling based on the single-layer, three-layer and the whole shielding case simplified modeling, which plays an important role on the improvement of the overall operation effect of electrical equipment in future.

\section{References}

[1]Poljak D, Kovač N, Kraljević S, et al. Simplified modeling of the human body exposed to power substation electric field using boundary element analysis[J]. Modelling in Medicine \& Biology VII, 2007:213-221.

[2]Jiang H L, Zeng K, Liu J M, et al. Analysis and Calculation of Substation's Internal Electric Field Intensity Caused by Incoming and Outgoing Lines[J]. Applied Mechanics \& Materials, 2013, 291-294:2428-2431.

[3]Cui X S, Jian-Xiong L I, Chen Z T, et al. Modeling and simulation of electromagnetic radiation interference in switched mode power supply[J]. Chinese Journal of Power Sources, 2014.

[4]Rakopoulos C D, Andritsakis E C, Hountalas D T. The influence of the exhaust system unsteady gas flow and insulation on the performance of a turbocharged diesel engine[J]. Heat Recovery Systems \& Chp, 1995, 15(1):51-72. 
[5]Zhang Z, Lee W J, Dini D A. Grounding and Isolation of Sensitive Measurement Equipment for Arc Flash Testing at High Power Lab[J]. IEEE Transactions on Industry Applications, 2015:1-1. 